\title{
Integrated ElectroBiocatalysis for Amine Alkylation with Alcohols
}

DOI:

$10.1002 /$ cctc. 202001757

\section{Document Version}

Accepted author manuscript

Link to publication record in Manchester Research Explorer

\section{Citation for published version (APA):}

Greaney, M., Turner, N., Dryfe, R., \& Penafiel, I. (2021). Integrated ElectroBiocatalysis for Amine Alkylation with Alcohols. ChemCatChem, 13(3), 864-867. https://doi.org/10.1002/cctc.202001757

\section{Published in:}

ChemCatChem

\section{Citing this paper}

Please note that where the full-text provided on Manchester Research Explorer is the Author Accepted Manuscript or Proof version this may differ from the final Published version. If citing, it is advised that you check and use the publisher's definitive version.

\section{General rights}

Copyright and moral rights for the publications made accessible in the Research Explorer are retained by the authors and/or other copyright owners and it is a condition of accessing publications that users recognise and abide by the legal requirements associated with these rights.

\section{Takedown policy}

If you believe that this document breaches copyright please refer to the University of Manchester's Takedown Procedures [http://man.ac.uk/04Y6Bo] or contact uml.scholarlycommunications@manchester.ac.uk providing relevant details, so we can investigate your claim.

\section{OPEN ACCESS}




\title{
Integrated Electro-Biocatalysis for Amine Alkylation with Alcohols
}

\author{
Itziar Peñafiel, ${ }^{1,2}$ Robert A.W. Dryfe, ${ }^{1 *}$ Nicholas J. Turner,${ }^{1,2 *}$ Michael F. Greaney ${ }^{1 *}$
}

1. Department of Chemistry, The University of Manchester, Oxford Road, Manchester M13 9PL, UK. E-mail: michael.greaney@manchester.ac.uk

2. Future Biomanufacturing Research Hub, University of Manchester, Manchester Institute of Biotechnology, 131 Princess Street, Manchester M1 7DN, UK.

Supporting information for this article is given via a link at the end of the document.

\begin{abstract}
The integration of electro and bio-catalysis offers new ways of making molecules under very mild, environmentally benign conditions. We show that TEMPO mediated electro-catalytic oxidation of alcohols can be adapted to work in aqueous buffers, with minimal organic co-solvent, enabling integration with biocatalytic reductive amination using the AdRedAm enzyme. The combined process offers a new approach to amine alkylation with native alcohols, a key bond formation in the chemical economy that is currently achieved via precious metal-catalyzed hydrogen-borrowing technologies. The electrobio transformation is effective for primary and secondary alcohols undergoing coupling with allyl, propargyl, benzyl, and cyclopropyl amines, and has been adapted for use with solidsupported $A d R e d A m$ for ease of operation.
\end{abstract}

The integration of different catalysis regimes can create new ways of building molecules, stimulating different disconnections with enhanced process sustainability and efficiency. Biocatalysis, in particular, offers exciting potential for integrated catalysis as the requisite reaction conditions (aqueous, mild temperatures and dilute concentrations) have historically dictated separate processing from other reactions in a synthetic sequence. ${ }^{1}$ Recent developments in merging biocatalysis with transition metal, ${ }^{2}$ photoredox, ${ }^{3}$ and organo- ${ }^{4}$ catalytic transformations have challenged this traditional model and created some highly innovative transformations that could not have been achieved under a single catalysis regime.

Our interest in developing new integrated biocatalysis systems ${ }^{5}$ motivated us to examine electro-catalysis as a possible partner technology. Electro-synthesis is undergoing a vigorous renaissance in the literature ${ }^{6}$ as chemists seek to exploit its enormous potential for sustainable synthesis, using cheap and potentially renewable energy for redox transformations. Electrobio processes have been extensively studied in areas such as fuel cells, biosensors, waste remediation, and co-factor recycling ${ }^{7}$ but the analogous integration has yet to be widely explored for chemical synthesis. $^{8}$

We chose to study the direct coupling of simple alcohols (1) and amines (2) as a putative electro-biocatalytic process (Scheme 1.1). This transformation is key to the future chemical economy as it creates a valuable $\mathrm{C}-\mathrm{N}$ bond from readily available feedstocks, with excellent atom economy, in principle generating water as the only by-product. The low native reactivity of alcohols precludes direct amination using classical stoichiometric methods, but the reaction can be achieved using hydrogen-borrowing catalysis. ${ }^{9}$ This richly innovative chemo-catalysis method takes transfer-hydrogenation metal complexes, initially from the precious platinum group (e.g. Ir complex 4) but more recently encompassing the earth-abundant first row transition metals (e.g. Mn complex 5), ${ }^{9 \mathrm{~d}}$ and sets up an oxidation / condensation / reduction cycle (Scheme 1.2). Sophisticated pincer ligands are usually required, and the reaction proceeds at high temperature $\left(\mathrm{T}>100^{\circ} \mathrm{C}\right.$ ). Biocatalytic hydrogen borrowing has also been achieved for amine-alcohol coupling although the inherent reversibility of the systems limits the conversions that can be obtained when employing oxidoreductases. ${ }^{10}$ An electrooxidation integrated with a biocatalytic reductive amination could offer a simple alternative, with potential for mild, sustainable reaction conditions and high conversions.

1. Amine alkylation

$$
{ }_{2}^{1}{ }_{1}^{\mathrm{OH}}+\mathrm{R}^{3} \mathrm{RH}_{2} \longrightarrow \mathrm{R}_{3}^{1}{\stackrel{\mathrm{C}}{\mathrm{C}^{2}}}_{\mathrm{R}^{2}}^{\mathrm{NHR}^{3}}+\mathrm{H}_{2} \mathrm{O}
$$

2. Prior art - Borrowing hydrogen catalysis

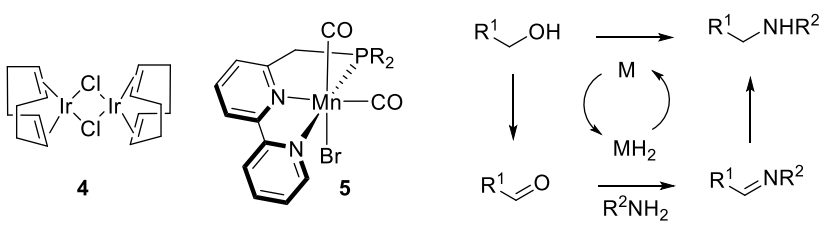

3. Proposed ElectroBioCatalysis

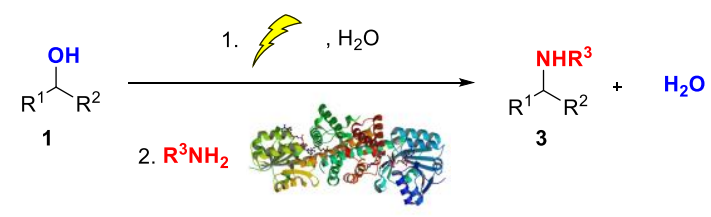

Scheme 1. Integrated electro-biocatalysis

We initially focused on the biocatalytic reductive amination component. Enzymatic reductive amination has recently been 
demonstrated for ketones using $\mathrm{NAD}(\mathrm{P}) \mathrm{H}$ - dependent imine reductases (IREDs). ${ }^{11}$ In most of the cases excess amine is needed in order to get good conversions, as IREDs' principal role is to catalyze the reduction of pre-formed imines. ${ }^{12}$ The Turner laboratory has recently discovered the fungal reductive aminases (RedAms), a sub-group of IREDs able to efficiently catalyze the reductive amination of a range of ketones at low ketone to amine ratio, which suggests that they catalyse imine formation in addition to imine reduction. ${ }^{13}$ We selected the reductive aminase AdRedAm, from Ajellomyces dermatidis, as the best candidate for integrative studies, due to its ability to participate in enzymatic cascades, high substrate tolerance and potential for preparative scale reactions.

Based on the previously reported activity of $A d R e d A m$ with a range of ketones, ${ }^{14}$ we investigated the ability of this enzyme to also perform the reductive amination of aliphatic aldehyde substrates including benzaldehyde, phenylpropionaldehyde and butyraldehyde (Scheme 2). We were pleased to observe excellent conversions for coupling these aldehydes with allyl, benzyl, and propargyl amines into the secondary amines $\mathbf{3 a - 3} \mathbf{i}$, under aqueous conditions containing $5 \%(\mathrm{v} / \mathrm{v}) \mathrm{DMSO}$ at $\mathrm{pH} 7.4 .^{15}$
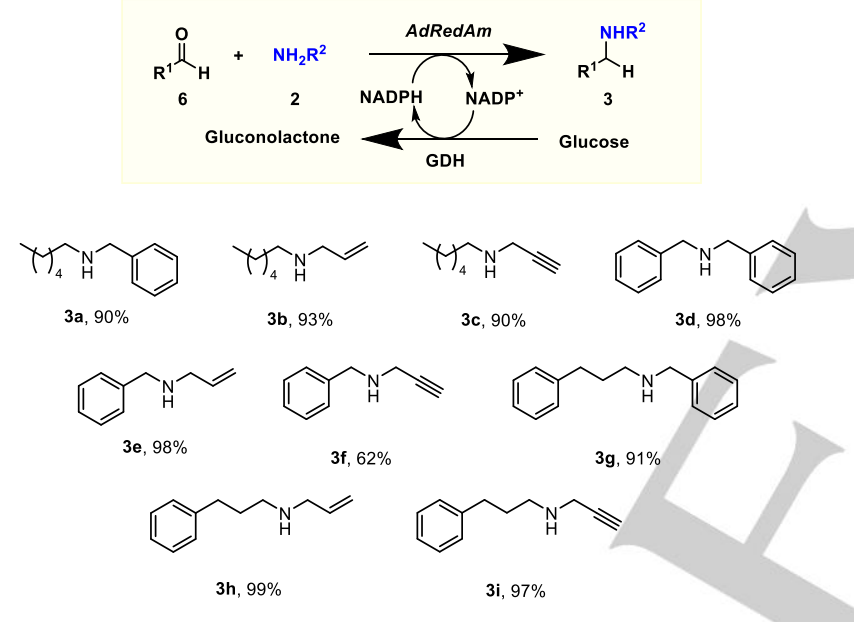

Scheme 2. AdRedAm reductive amination of aldehydes. Reaction Conditions: aldehyde (10mM), amine (2 equiv.), glucose (4 equiv.), $\mathrm{NADP}^{+}(1 \mathrm{mM})$, AdRedAm (1mg/mL), GDH $(0.5 \mathrm{mg} / \mathrm{mL}), 5 \%(\mathrm{v} / \mathrm{v})$ DMSO, TRIS buffer $\mathrm{pH} 7.4$, $250 \mathrm{rpm}, 30^{\circ} \mathrm{C}, 24$ hour. Percentage conversions determined by GC.

Turning to the electro-catalytic reaction, we were attracted to the 2,2,6,6-tetramethylpiperidine-1-oxyl (TEMPO) electro-oxidation system as a scalable, catalytic and environmentally benign method for the oxidation of alcohols. ${ }^{16}$ The active species in TEMPO-mediated oxidation is oxoammonium $\mathbf{7}$, which is electrochemically generated from TEMPO through an anodic single electron transfer process and is able to oxidize alcohol 1 to the corresponding aldehyde or ketone $\mathbf{6}$ (Scheme 3.1). During this process, hydroxylamine $\mathbf{8}$ is generated and rapidly re-oxidized to the TEMPO radical in the presence of oxygen. Intermediate 9 has been proposed for the interaction of oxoammonium 7 and the alcohol 1 in basic conditions. ${ }^{16 b}$ Literature examples for the electrolytic TEMPO-mediated oxidation of alcohols generally require the employment of organic solvents in ratios between 30 and $95 \%$, in part due to the fact that TEMPO is sparingly soluble in polar electrolytic media. ${ }^{6 a}$ As our AdRedAm reductive amination tolerated a maximum of $5 \%(\mathrm{v} / \mathrm{v})$ DMSO before showing loss of activity, this divergence in reaction media was clearly an important challenge to solve for the development of an integrated process.

1. TEMPO oxidation of primary alcohols

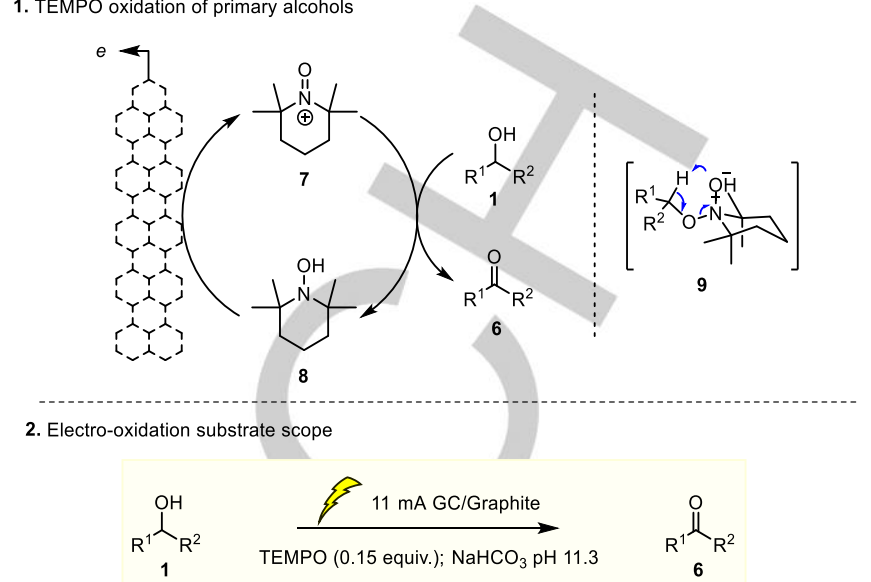

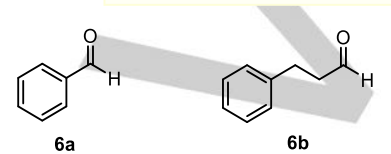
$(99 \%, 16 \mathrm{~h})$ $(95 \%, 24 \mathrm{~h})$<smiles>O=C/C=C/c1ccccc1</smiles>

$6 c$

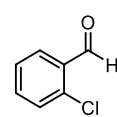

6d
$(43 \%, 3 \mathrm{~h})$

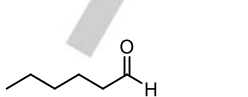

$6 \mathrm{e}$

$(85 \%, 48 \mathrm{~h})$

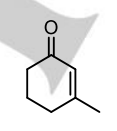

6h

$(95 \%, 16 \mathrm{~h})^{\star}$

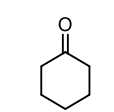

6

$(92 \%, 16 \mathrm{~h})^{*}$<smiles>C=C(C)C1CC=C(C)C(=O)C1</smiles>

$(87 \%, 16 \mathrm{~h})^{*}$

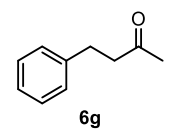

$(48 \%, 48 \mathrm{~h})^{\star}$

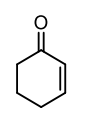

6]

Scheme 3. 1. TEMPO-mediated electrochemical alcohol oxidation. 2. Substrate tolerance of TEMPO-mediated electro-oxidation in water. Reaction conditions: Alcohol $(20 \mathrm{mM}) ; 0.1 \mathrm{M} \mathrm{NaHCO}_{3}$ aqueous buffer solution $\mathrm{pH} 11.3 ; 5 \%(\mathrm{v} / \mathrm{v})$ DMSO, rt. Percentage conversions determined by GC. * 0.2 equiv of TEMPO used.

Optimization of the electro-oxidation was conducted using a commercially available ElectraSyn device fitted with an undivided cell $\left(5.5 \mathrm{~cm}^{2}\right.$ per electrode for a liquid volume of $10 \mathrm{~mL}$, total current of $11 \mathrm{~mA}$ ). A study of TEMPO electro-oxidation in aqueous buffers was carried out with respect to electrode materials, equivalency, common additives, $\mathrm{pH}^{17}$ and reaction time dependence (see supporting information), establishing optimal conditions of 0.15 equivalents of TEMPO, $\mathrm{pH} 11.3$ using $\mathrm{NaHCO}_{3}$ buffer with a glassy carbon (GC) working electrode and graphite counter electrode. A range of primary and secondary alcohols were then successfully oxidized under these aqueous electrocatalytic conditions (Scheme 3.2). Highest conversions were obtained for aromatic primary alcohols $6 \mathbf{a}$ and $\mathbf{6 b}$. The system allows the presence of halogen groups in the aromatic ring, although the reaction should be stopped earlier to avoid the generation of several by-products by halogen group reaction at the cathode in our undivided cell. (6d) Primary aliphatic alcohols such as 1-hexanol (6e) provided lower conversions, which is consistent with the literature reports. ${ }^{18}$ Our system also allowed the electro-oxidation of secondary aliphatic alcohols, although the addition of 0.2 equivalents of TEMPO were needed $(\mathbf{6 f - 6 j})$. It is 
remarkable that only traces of the corresponding carboxylic acids were observed during the oxidation of linear aliphatic alcohols (1c and 1e). Overall the reaction was very clean with excellent specificity, using the cheap GC as the WE and proceeding under aqueous conditions with no requirement for additional bases or electrolytes (e.g. tetraalkylammonium salts).

Initial investigations into integrating the electro/bio catalysis involved taking aliquots of the ketones and aldehyde products direct from the electro-oxidation and adding them to solutions of aqueous buffer containing allyl amine, AdRedAm, GDH, glucose and cofactor $\mathrm{NADP}^{+}$. Unfortunately, the conversions were very low, suggesting a $\mathrm{pH}$ and media incompatibility - the very basic conditions for optimal electrosynthesis in carbonate buffer $(\mathrm{pH} 11)$ were not compatible with enzymatic reductive amination in TRIS media (optimal pH 7.8). We re-examined the biotransformation in a series of buffers at different $\mathrm{pH}$ values (see supporting information, Scheme S4), and saw substantial deterioration in activity in alkaline media (e.g. $50 \%$ conversion using $\mathrm{NaHCO}_{3}$ buffer $\mathrm{pH}$ 11.3). However, encouraging results were obtained in buffer mixtures, with a conversion of $89 \%$ at $\mathrm{pH} 8.0$ in $1: 2$ mixture of $\mathrm{NaHCO}_{3} /$ TRIS system. We were delighted to find that this medium was effective for an integrated electrobio process; 1 hexanol undergoing electro-catalytic TEMPO oxidation at $\mathrm{pH} 11.3$ followed by addition to AdRedAm in aq TRIS buffer for amination (overall $\mathrm{pH} 8.0$ ) affording a good $76 \%$ conversion. The reaction conditions were general for the primary alcohol and amine components previously examined in Schemes 2 and 3, delivering the secondary amine products $\mathbf{3 a}-\mathbf{3} \mathbf{p}$ in good to excellent conversion (Scheme 4). The integrated reaction was also effective for cyclohexanol as a secondary substrate (3j and $\mathbf{3 k}$ ), but 1-phenylbutan-3-ol was problematic, affording low yields of the reductively aminated products $3 \mathbf{I}$ and $3 \mathrm{~m}$. We were also able to introduce cyclopropylamine as a secondary alkyl amine component, efficiently transforming into $\mathbf{3 n}$ and $\mathbf{3 o}$ with aldehyde substrates.

Improving the scale of the process required some optimization around the $20 \mathrm{~mL}$ reaction volume of the Electrasyn apparatus (see supporting information). Alcohol concentrations above $50 \mathrm{mM}$ started to generate significant quantities of pinacol condensation products, and we established $40 \mathrm{mM}$ alcohol as optimal. The reaction mixture $(20 \mathrm{~mL})$ containing the electrochemically generated oxidation product and TEMPO at $\mathrm{pH}$ 11.3 could then be added direct to a $40 \mathrm{~mL}$ solution containing the enzymatic system, cofactor, glucose and amine in TRIS buffer at $\mathrm{pH}$ 7.4. After 24 hours at 30 degrees and $250 \mathrm{rpm}$ the corresponding amines $\mathbf{3 a}, \mathbf{3 b}, \mathbf{3} \mathbf{h}-\mathbf{3 k}, \mathbf{3 n}$ and $\mathbf{3 0}$ were isolated in good overall yields (51-73\%).

Finally, we turned our attention to strengthening the processivity of the method through enzyme immobilization, a fundamental consideration for industrial biotransformations where work-up and catalyst re-use are critical. Our previous work had identified the increased stability of RedAm enzymes on a functionalised pore glass support, ${ }^{19}$ so we decided to immobilize our enzymatic system ( $A d$ RedAm and GDH) on EziG Amber support. Pleasingly, we observed successful re-use in three cycles for the 3-phenylpropan-1-ol substrate, forming amine $3 \mathrm{~h}$ in $70 \%, 70 \%$, and $57 \%$ in three consecutive cycles. A fourth cycle gave diminished yields $(<20 \%)$.

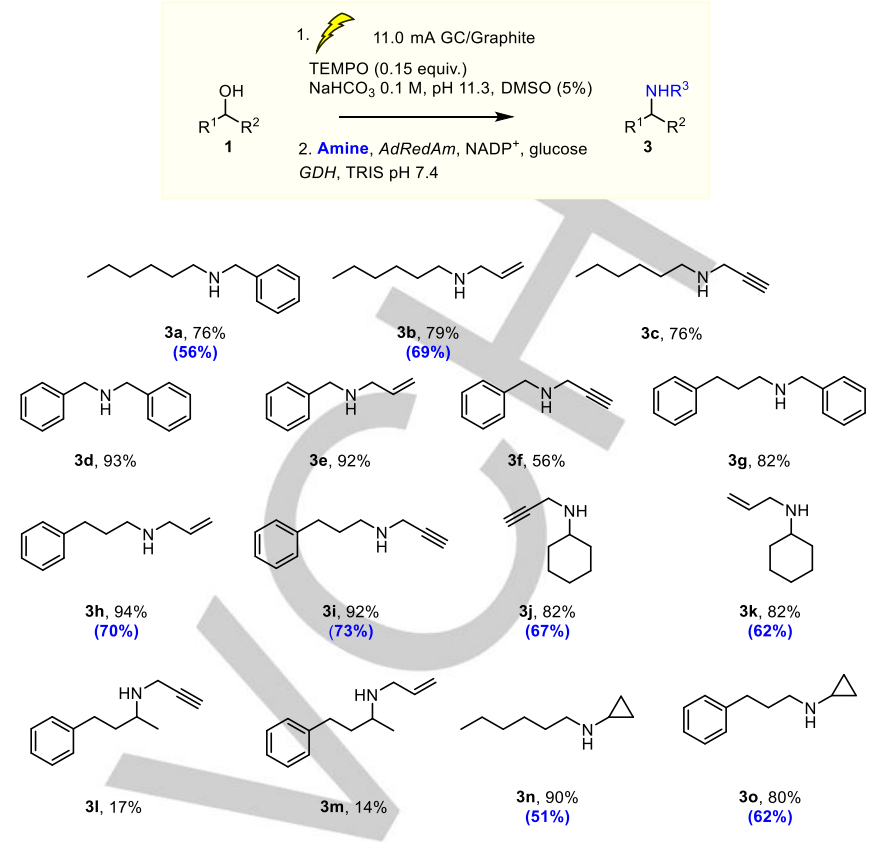

Scheme 4. Reaction Conditions: 1) Electrolytic oxidation: alcohol (20mM), TEMPO (0.15 equiv), $\mathrm{NaHCO}_{3} 0.1 \mathrm{M} \mathrm{pH} 11.3,5 \%$ (v/v) DMSO, rt, 18 hours; 2 ) Reductive amination: amine (2 equiv.), glucose (4 equiv.), NADP+ $(1 \mathrm{mM})$, AdRedAm ( $1 \mathrm{mg} / \mathrm{mL}), \mathrm{GDH}(0.5 \mathrm{mg} / \mathrm{mL})$, TRIS buffer solution $\mathrm{pH} 7.4,250 \mathrm{rpm}$, $30{ }^{\circ} \mathrm{C}, 24$ hours. Isolated yields in blue.

In summary we have developed an integrated electrobio-catalytic approach to amine alkylation. The process harnesses the versatility of two powerful catalysis systems: TEMPO electrooxidation and AdRedAm biocatalytic reductive amination, merging them via the development of a single compatible aqueous reaction medium with minimal organic solvent. The reaction proceeds under exceptionally mild conditions, with no requirements for precious metals and accompanying ligands. Further applications of electrobio-catalysis for chemical synthesis are underway in our laboratories.

Keywords: biocatalysis $\cdot$ electrocatalysis $\cdot$ amines $\cdot$ reductive amination •

Acknowledgements: We thank the EPSRC UK Catalysis Hub for funding. 
[1] Reviews: a) X. Huang, M. Cao, H. Zhao, Curr. Opin. Chem. Biol. 2020, 55, 161. b) F. Rudroff, M. D. Mihovilovic, H. Gröger, R. Snajdrova, H. Iding, U. T. Bornscheuer, Nat. Catal. 2018, 1, 12.

[2] a) C. A. Denard, J. F. Hartwig, H. Zhao, ACS Catal. 2013, 3 , 2856. b) H. Gröger, W. Hummel, Curr. Opin. Chem. Biol. 2014, 19, 171.

[3] a) L. Schmermund, V. Jurkas, F. Feyza Özgen, G. D. Barone, H. C. Büchsenschütz, C. K. Winkler, S. Schmidt, R. Kourist, W. Kroutil, ACS Catal. 2019, 9, 4115. b) F. F. Özgen, M. E. Runda, S. Schmidt, ChemBioChem, 2020, Early view, doi:10.1002/cbic.202000587.

[4] F. R. Bisogno, M. G. Lopez-Vidal, G. de Gonzalo, Adv. Synth. Catal. 2017, 359, 2026.

[5] a) S. C. Cosgrove, M. P. Thompson, S. T. Ahmed, F. Parmeggiani, N. J. Turner, Angew. Chem. Int. Ed. 2020, 59, 18156. b) M. Odachowski, M. F. Greaney, N. J. Turner, ACS Catalysis 2018, 8, 10032. c) J. Latham, J.-M. Henry, H. H. Sharif, B. R. K. Menon, S. A. Shepherd, M. F. Greaney, J. Micklefield, Nat. Commun. 2016, 7, 11873 .

[6] a) M. Yan, Y. Kawamata, P. S. Baran, Chem. Rev. 2017, 117 , 13230. b) C. Schotten, T. P. Nicholls, R. A. Bourne, N. Kapur, B. N. Nguyen, C. E. Willans Green Chem. 2020, 22, 3358.

[7] Reviews: a) R. D. Milton, S. D. Minteer, J. R. Soc. Interface 2017, 14: 20170253. b) S. V. Mohan, G. Velvizhi, K. V. Krishna, M. L. Babu, Bioresour. Technol. 2014, 165, 355.

[8] a) D. P. Hickey, M. S. McCammant, F. Giroud, M. S. Sigman, S. D. Minteer, J. Am. Chem. Soc. 2014, 136, 15917. b) A. AlShameri, M.-C. Petrich, K. j. Puring, U.-P. Apfel, B. M. Nestl, L. Lauterbach, Angew. Chem. 2020, 132, 11021. Angew. Chem. Int. Ed. 2020, 59, 10929.

[9] a) A. Corma, J. Navas, M. J. Sabater, Chem. Rev. 2018, 118, 1410. b) B. G. Reed-Berendt, K. Polidano, L. C. Morrill, Org. Biomol. Chem. 2019, 17, 1595. c) R. Grigg, T. R. B. Mitchell, S. Sutthivaiyakit, N. Tongpenyai, Chem. Commun. 1981, 611. d) S. Elangovan, J. Neumann, J.-B. Sortais, K. Junge, C. Darcel and M. Beller, Nat. Commun. 2016, 7, 12641.
[10] F. G. Mutti, T. Knaus, N. S. Scrutton, M. Breuer, N. J. Turner, Science 2015, 349, 1525.

[11] a) T. Huber, L. Schneider, A. Präg, S. Gerhardt, O. Einsle, M. Müller, ChemCatChem 2014, 6, 2248. b) P. N. Scheller, M Lenz, S. C. Hammer, B. Hauer, B. M. Nestl, ChemCatChem 2015, 7, 3239. c) D. Wetzl, M. Gand, A. Ross, H. Müller, P. Matzel, S. P. Hanlon, M. Müller, B. Wirz, M. Höhne, H. Iding, ChemCatChem 2016, 8, 2023. e) J. Mangas-Sanchez, S. P. France, S. L. Montgomery, G. A. Aleku, H. Man, M. Sharma, J. I. Ramsden, G. Grogan, N. J. Turner, Curr. Opin. Chem. Biol. 2017 , 37,19 .

[12] K. Faber, W.-D. Fessner, N. J. Turner, Biocatalysis in Organic Synthesis, Georg Thieme Verlag, 2015.

[13] G. A. Aleku, S. P. France, H. Man, J. Mangas-Sanchez, S. L. Montgomery, M. Sharma, F. Leipold, S. Hussain, G. Grogan, N. J. Turner, Nat. Chem. 2017, 9, 961.

[14] M. Sharma, J. Mangas-Sanchez, S. P. France, G. A. Aleku, S. L. Montgomery, J. I. Ramsden, N. J. Turner, G. Grogan, ACS Catal. 2018, 8, 11534 .

[15] For a recent industrial application of IREDs with aldehyde substrates, see: M. Schober, C. MacDermaid, A. A. Ollis, S. Chang, D. Khan, J. Hosford, J. Latham, L. A. F. Ihnken, M. J. B. Brown, D. Fuerst, M. J. Sanganee, G.-D. Roiban, Nat. Catal. 2019, 2, 909.

[16] a) W. Summermann, U. Deffner, Tetrahedron 1975, 31, 593. Reviews: b) H. A. Beejapur, Q. Zhang, K. Hu, L. Zhu, J. Wang, Z. Ye, ACS Catal. 2019, 9, 2777. c) J. E. Nutting, M. Rafiee, S. S Stahl, Chem. Rev. 2018, 118, 4834. d) L. Tebben, A. Studer, Angew. Chem. 2011, 123, 5138. Angew. Chem. Int. Ed. 2011, 50, 5034

[17] J. T. Hill-Cousins, J. Kuleshova, R. A. Green, P. R. Birkin, D. Pletcher, T. J. Underwood, S. G. Leach, R. C. D. Brown, ChemSusChem 2012, 5, 326.

[18] S. D. Ahn, A. C. Fisher, A. Buchard, S. D. Bull, A. M. Bond, F. Marken, Electroanalysis 2016, 28, 2093.

[19] M. P. Thompson, S. R. Derrington, R. S. Heath, J. L. Porter, J. Mangas-Sanchez, P. N. Devine, M. D. Truppo, N. J. Turner, Tetrahedron 2019, 75, 327-334. 


\section{Entry for the Table of Contents}
${ }_{\mathrm{R}^{1}}^{\mathrm{OH}}+\mathrm{R}^{2} \mathrm{NH}_{2}$

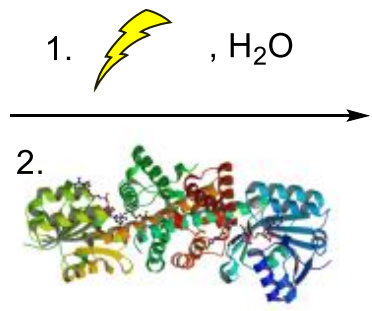
$\mathrm{R}^{1} \stackrel{\mathrm{NHR}}{\mathrm{R}^{2}}+\mathrm{H}_{2} \mathrm{O}$

An integrated electrobiocatalytic amine alkylation reaction is reported that proceeds under very mild, environmentally benign conditions. Using a combination of aqueous TEMPO electrocatalysis and AdRedAm biocatalytic reductive amination, a range of primary and secondary alcohols can be coupled with allyl, propargyl, benzyl, and cyclopropyl amines in a single operation.

Institute and/or researcher Twitter usernames: @greaneygroup 